\section{JURNAL EKONOMI EFEKTIF}

ISSN : $2622-8882$, E-ISSN : 2622-9935

Jurnal Ekonomi Efektif, Vol. 4, No. 2, Januari 2022

@ Prodi Manajemen Fakultas Ekonomi

Universitas Pamulang

\title{
PENGARUH KUALITAS PRODUK TERHADAP KEPUTUSAN PEMBELIAN TANAMAN HIAS PADA PT CIPTA ASRI FLORIST DI JAKARTA
}

\author{
Dicky Akbar Yulianvera ${ }^{1}$, Ruknan $^{2 *}$ \\ Universitas Pamulang, Tangerang Selatan, Banten, Indonesia \\ dickyylvr@gmail.com ${ }^{1}, \underline{\text { dosen01757@unpam.ac.id }{ }^{2 *}}$
}

Manuskrip: Oktober -2021; Ditinjau: November: -2021; Diterima: November-2021; Online: Januari -2022; Diterbitkan: Januari-2022

\begin{abstract}
ABSTRAK
Penelitian ini bertujuan untuk mengetahui pengaruh kualitas produk terhadap keputusan pembelian tanaman hias pada PT. Cipta Asri Florist di Jakarta. Metode yang digunakan adalah explanatory research dengan sampel sebanyak 100 responden. Teknik analisis menggunakan analisis statistik dengan pengujian regresi, korelasi, determinasi dan uji hipotesis. Hasil penelitian ini variabel kualitas produk diperoleh nilai rata-rata skor sebesar 3,428 dengan kriteria baik. Variabel keputusan pembelian diperoleh nilai rata-rata skor sebesar 3,835 dengan kriteria baik. Kualitas produk berpengaruh positif dan signifikan terhadap keputusan pembelian dengan nilai persamaan regresi $\mathrm{Y}=7,788+0,892 \mathrm{X}$, dan nilai koefisien korelasi 0,781 atau memiliki tingkat hubungan yang kuat dengan nilai determinasi 61,0\%. Uji hipotesis diperoleh signifikansi $0,000<0,05$.
\end{abstract}

Kata Kunci: Kualitas Produk, Keputusan Pembelian

\section{ABSTRACT}

This study aims to determine the effect of product quality on purchasing decisions of ornamental plants at PT. Cipta Asri Florist in Jakarta. The method used is explanatory research with a sample of 100 respondents. The analysis technique uses statistical analysis with regression, correlation, determination and hypothesis testing. The results of this research variable product quality obtained an average score of 3,428 with good criteria. The purchase decision variable obtained an average score of 3.835 with good criteria. Product quality has a positive and significant effect on purchasing decisions with a regression equation value of $Y$ $=7.788+0.892 X$, and a correlation coefficient value of 0.781 or has a strong relationship with a determination value of $61.0 \%$. Hypothesis testing obtained a significance of 0.000 $<0.05$.

Keywords: Product Quality, Purchase Decision 


\section{PENDAHULUAN}

\section{A. Latar Belakang}

Kualitas produk merupakan hal penting yang harus diperhatikan oleh setiap perusahaan apabila menginginkan produk yang dihasilkan dapat bersaing dipasar. Persepsi masing-masing konsumen akan suatu produk berbeda-beda. Kualitas Produk Menurut Kotler (2012: 283) adalah kemampuan sebuah produk dalam memperagakan fungsinya, hal ini termasuk keseluruhan durabilitas, reliabilitas, ketepatan, kemudahan pengoperasian dan reparasi produk juga atribut produk lainnya. Bentuk produk harus meliputi ukuran serta struktur fisik produk. Fitur meliputi aspek-aspek keistimewaan, karakteristik serta ragam keuntungan yang diitegrasikan atau dibawa didalam suatu produk terpapar kepada konsumen atau pelanggan. Termasuk didalamnya kesan kualitas, keunggulan merk serta totalitas mutu dan gaya atau penampilan produk serta kesan konsumen terhadap produk.

Tanaman Hias daun Aglamena memiliki bentuk daun yang pada dasarnya tanaman fuchsia ini adalah tanaman yang hidup disemak belukar dan memiliki ukuran yang kecil. Ciri-ciri produk Hortikultura mudah, rusak bila disimpan tanpa perlakuan khusus misalnya dengan perlakukan suhu rendah komponen utama mutu produk ditentukan kandungan air dan bukan ditentukan oleh kandungan bahan kering karena konsumsinya dalam keadaan. Tanaman Hortikultura memiliki prospek pengembangan yang baik karena memiliki nilai ekonomi yang tinggi dan potensi pasar yang terbuka lebar, baik didalam negeri maupun luar negeri.

Ketahanan, memiliki daya tahan yang berbeda-beda terhadap lingkungan seperti intensitas cahaya, kelembaban, sirkulasi udara temperatur. Tanaman hias yang tahan akan intensitas cahaya matahari yang rendah dapat digunakan sebagai tanaman hias indoor. Juga tahan terhadap udara kering dengan sedikit sirkulasi dan tahan namun demikian bukan berarti tanaman tersebut tahan selamanya dalam ruangan. Rotasi minimal dua minggu sekali.

Menurut Kotler (2012:166) Keputusan Pembelian adalah proses keputusan pembelian terdiri lima tahap yang dilakukan oleh seorang konsumen sebelum sampai pada keputusan pembelian dan selanjutnya pasca pembelian. Pengenalan kebutuhan pada tanaman hias sangat penting, pada tahap awal keputusan membeli konsumen/pelanggan diharuskan mengenali adanya masalah kebutuhan. Akan produk tanaman hias yang akan dibeli. Setelah melakukan pengenalan kebutuhan maka dilakukan pencarian informasi sebanyak-banyaknya kemudian dilakukan evaluasi alternatif untuk memilih produk yang akan dibeli oleh konsumen/pelanggan.

Keputusan Pembelian Konsumen Memutuskan untuk membeli. Perusahaan menyusun strategi usaha dan pemasarannya agar mampu lebih dekat dengan konsumen, mengatasi ancaman persaingan, dan memperkuat keunggulan bersaingnya. Perusahaan dituntut untuk mampu mengatasi perubahaan pasar dan reaktif dalam memanfaatkan peluang yang menguntungkan disamping menghindari ancaman, jugamerupakan prasyarat utama untuk mencapai keberhasilan pada era pasar yang memiliki persaingan ketat.

Produk menjadi instrumen penting untuk mencapai kesuksesan dan kemakmuran pada perusahaan modern. Perkembangan teknologi, peningkatan persaingan global, serta kebutuhan dan keinginan pasar mengharuskan perusahaan melakukan pengembangan produk yang terus- menurus. Hanya ada dua pilihan yaitu sukses dalam pengembangan produk sehingga meghasilkan produk yang unggul, atau gagal dalam pencapaian tujuan bisnisnya karena produkyang tidak mampu bersaing dipasar. Perusahaan harus berusaha menciptakan produk untuk memenuhi 
keperluan dan kebutuhan konsumen misalkan dalam industri tanaman hias.

Berdasarkan pemaparan di atas, maka penulis tertarik untuk mengadakan penelitian lebih lanjut dengan judul "Pengaruh Kualitas Produk Terhadap Keputusan Pembelian Tanaman Hias Pada PT. Cipta Asri Florist di Jakarta".

\section{B. Rumusan Masalah}

1. Bagaimana kualitas produk pada PT. Cipta Asri Florist di Jakarta ?.

2. Bagaimana keputusan pembelian pada PT. Cipta Asri Florist di Jakarta ?.

3. Adakah pengaruh antara kualitas produk terhadap keputusan pembelian pada PT. Cipta Asri Florist di Jakarta?.

\section{Tujuan Penelitian}

1. Untuk mengetahui kondisi kualitas produk pada PT. Cipta Asri Florist di Jakarta.

2. Untuk mengetahui kondisi keputusan pembelian pada PT. Cipta Asri Florist di Jakarta.

3. Untuk mengetahui pengaruh kualitas produk terhadap keputusan pembelian pada PT. Cipta Asri Florist di Jakarta.

\section{TINJAUAN PUSTAKA}

\section{Kualitas Produk}

Menurut Kotler dan Armstrong (2019:349) "Kualitas Produk merupakan sesuatu yang bisa ditawarkan kepasar untuk diperhatikan, dimiliki, digunakan, atau dikonsumsi yang bias memuaskan keinginan dan kebutuhan”.

\section{Keputusan Pembelian}

Menurut Kotler dan Amstrong (2019) berpendapat "perilaku konsumen merupakan sebuah pendekatan penyesuaian masalah yang terdiri dari lima tahap yang dilakukan konsumen. Kelima tahap tersebut adalah pengenalan masalah, pencarian informasi, evaluasi alternatif, keputusan pembelian, dan perilaku pasca pembelian".

\section{III.METODE PENELITIAN}

\section{Populasi}

Yang dijadikan sebagai populasi dalam penelitian ini adalah responden yang berjumlah 100 responden PT. Cipta Asri Florist di Jakarta

\section{Sampel}

Teknik pengambilan sampling dalam penelitian ini adalah sampel jenuh, dimana semua anggota populasi dijadikan sebagai sampel. Dengan demikian sampel dalam penelitian ini sampel yang digunakan berjumlah 100 responden.

\section{Jenis Penelitian}

Jenis penelitian yang dipakai adalah asosiatif, dimana tujuannya adalah untuk mengetahui atau mencari keterhubungan antara variabel independen terhadap variabel dependennya

\section{Metode Analisis Data}

Dalam menganalisis data digunakan uji validitas, uji reliabilitas, analisis regresi linier sederhana, analisis koefisien korelasi, analisis koefisien determinasi dan pengujian hipotesis.

\section{IV.HASIL PENELITIAN}

\section{Analisis Deskriptif}

Pada pengujian ini digunakan untuk mengetahui skor minimum dan maksimum 
skor tertinggi, ratting score dan standar deviasi dari masing-masing variabel. Adapun hasilnya sebagai berikut:

\begin{tabular}{|c|c|c|c|c|c|}
\hline \multicolumn{6}{|c|}{$\begin{array}{c}\text { Tabel 1. Hasil Analisis Descriptive Statistics } \\
\text { Descriptive Statistics }\end{array}$} \\
\hline & $\mathrm{N}$ & Minimum & Maximum & Mean & $\begin{array}{l}\text { Std. } \\
\text { Deviation }\end{array}$ \\
\hline Kualitas Produk (X) & 100 & 28 & 44 & 34.28 & 3.712 \\
\hline Keputusan Pembelian (Y) & 100 & 29 & 49 & 38.35 & 4.239 \\
\hline Valid N (listwise) & 100 & & & & \\
\hline
\end{tabular}

Kualitas produk diperoleh varians minimum sebesar 28 dan varians maximum 44 dengan ratting score sebesar 3,428 dengan standar deviasi 3,712. Skor ini termasuk pada rentang sakala 3,40-4,19 dengan kriteria baik atau setuju. Keputusan pembelian diperoleh varians minimum sebesar 29 dan varians maximum 49 dengan ratting score sebesar 3,835 dengan standar deviasi 4,239. Skor ini termasuk pada rentang sakala 3,40 - 4,19 dengan kriteria baik atau setuju.

\section{Analisis Kuantitatif}

Pada analisis ini dimaksudkan untuk mengetahui pengaruh variabel independen terhadap variabel dependen. Adapun hasil pengujian sebagai berikut:

\section{a. Analisis Regresi Linier Sederhana}

Uji regresi ini dimaksudkan untuk mengetahui perubahan variabel dependen jika variabel independen mengalami perubahan. Adapun hasil pengujiannya sebagai berikut:

Tabel 2. Hasil Pengujian Regresi Linier Sederhana

\begin{tabular}{|c|c|c|c|c|c|}
\hline \multirow[b]{3}{*}{ Model } & \multicolumn{4}{|c|}{ Coefficients $^{\mathrm{a}}$} & \multirow[b]{3}{*}{ Sig. } \\
\hline & \multicolumn{2}{|c|}{$\begin{array}{l}\text { Unstandardized } \\
\text { Coefficients }\end{array}$} & \multirow{2}{*}{$\begin{array}{c}\text { Standardized } \\
\text { Coefficients } \\
\text { Beta }\end{array}$} & \multirow[b]{2}{*}{$\mathrm{t}$} & \\
\hline & $\mathrm{B}$ & Std. Error & & & \\
\hline $1 \quad$ (Constant) & 7.788 & 2.485 & & 3.134 & .002 \\
\hline Kualitas Produk (X) & .892 & .072 & .781 & 12.370 & .000 \\
\hline
\end{tabular}

a. Dependent Variable: Keputusan Pembelian (Y)

Berdasarkan hasil pengujian pada tabel di atas, diperoleh persamaan regresi $\mathrm{Y}$ $=7,788+0,892 \mathrm{X}$. Dari persamaan tersebut dijelaskan sebagai berikut:

1) Konstanta sebesar 7,788 diartikan jika kualitas produk tidak ada, maka telah terdapat nilai keputusan pembelian sebesar 7,788 point.

2) Koefisien regresi kualitas produk sebesar 0,892 , angka ini positif artinya setiap ada peningkatan kualitas produk sebesar 0,892 point maka keputusan pembelian juga akan mengalami peningkatan sebesar 0,892 point.

\section{b. Analisis Koefisien Korelasi}

Analisis koefisien korelasi dimaksudkan untuk mengetahui tingkat kekuatan hubungan dari variabel independen terhadap variabel dependen. Adapun hasil pengujian sebagai berikut:

Tabel 3. Hasil Pengujian Koefisien Korelasi Kualitas Produk Terhadap Keputusan Pembelian.

Correlations $^{\text {b }}$

\begin{tabular}{llrr} 
& & \multicolumn{1}{c}{ Correlations $^{\text {Kualitas }}$} & \multicolumn{1}{c}{$\begin{array}{c}\text { Keputusan } \\
\text { Pembelian (Y) }\end{array}$} \\
\hline Kualitas Produk (X) & Pearson Correlation & 1 & $.781^{* *}$ \\
\cline { 2 - 4 } & Sig. (2-tailed) & & .000 \\
\hline Keputusan Pembelian (Y) & Pearson Correlation & $.781^{* *}$ & 1 \\
\hline
\end{tabular}




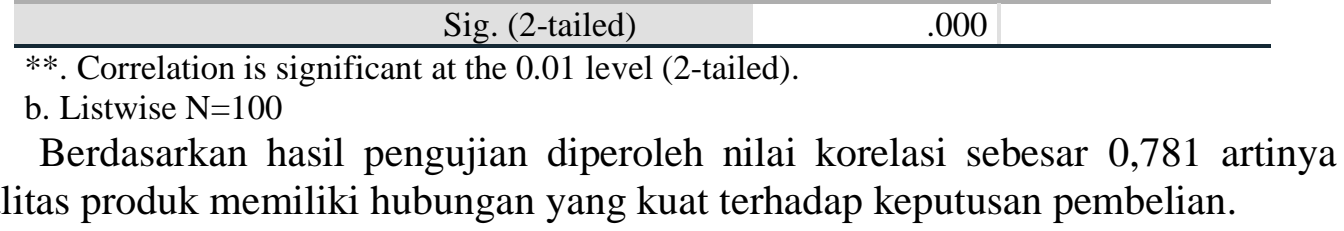

\section{c. Analisis Koefisien Determinasi}

Analisis koefisien determinasi dimaksudkan untuk mengetahui besarnya persentase pengaruh dari variabel independen terhadap variabel dependen. Adapun hasil pengujian sebagai berikut:

Tabel 4. Hasil Pengujian Koefisien Determinasi Kualitas Produk Terhadap

\section{Keputusan Pembelian.}

\begin{tabular}{|c|c|c|c|c|}
\hline \multicolumn{5}{|c|}{ Model Summary } \\
\hline Mod & $\mathrm{R}$ & R Square & Adjusted R Square & Std. Error of the Estimate \\
\hline 1 & $.781^{\mathrm{a}}$ & .610 & .606 & 2.662 \\
\hline
\end{tabular}

Predictors: (Constant), Kualitas Produk (X)

Berdasarkan hasil pengujian diperoleh nilai determinasi sebesar 0,610 artinya kualitas produk memiliki kontribusi pengaruh sebesar 61,0\% terhadap keputusan pembelian, sedangkan sisanya sebesar 39,0\% dipengaruhi oleh faktor lain yang tidak dilakukan penelitian.

\section{d. Uji Hipotesis}

Pengujian hipotesis dengan uji t digunakan untuk mengetahui hipotesis mana yang diterima. Rumusan hipotesis: Terdapat pengaruh yang signifikan kualitas produk terhadap keputusan pembelian.

Tabel 5. Hasil Uji Hipotesis Kualitas produk Terhadap Keputusan Pembelian. Coefficients $^{\mathrm{a}}$

\begin{tabular}{|c|c|c|c|c|c|}
\hline \multirow[b]{3}{*}{ Model } & \multicolumn{4}{|c|}{ Coemincients } & \multirow[b]{3}{*}{ Sig. } \\
\hline & \multicolumn{2}{|c|}{ Unstandardized Coefficients } & $\begin{array}{l}\text { Standardized } \\
\text { Coefficients }\end{array}$ & & \\
\hline & B & Std. Error & Beta & $\mathrm{t}$ & \\
\hline 1 (Constant) & 7.788 & 2.485 & & 3.134 & .002 \\
\hline Kualitas Produk (X) & .892 & .072 & .781 & 12.370 & .000 \\
\hline
\end{tabular}

a. Dependent Variable: Keputusan Pembelian (Y)

Berdasarkan hasil pengujian pada tabel di atas, diperoleh nilai t hitung $>\mathrm{t}$ tabel atau $(12,370>1,984)$, dengan demikian hipotesis yang diajukan bahwa terdapat pengaruh yang signifikan atara kualitas produk terhadap keputusan pembelian diterima.

\section{Pembahasan Hasil Penelitian}

\section{Kondisi Jawaban Responden Variabel Kualitas Produk}

Berdasarkan jawaban responden, variabel kualitas produk diperoleh ratting score sebesar 3,428 berada di rentang skala 3,40-4,19 dengan kriteria baik atau setuju.

\section{Kondisi Jawaban Responden Variabel Keputusan Pembelian}

Berdasarkan jawaban responden, variabel keputusan pembelian diperoleh ratting score sebesar 3,835 berada di rentang skala 3,40 - 4,19 dengan kriteria baik atau setuju.

\section{Pengaruh Kualitas Produk Terhadap Keputusan Pembelian}

Kualitas produk berpengaruh signifikan terhadap keputusan pembelian dengan persamaan regresi $\mathrm{Y}=7,788+0,892 \mathrm{X}$, nilai korelasi sebesar 0,781 atau memiliki hubungan yang kuat dengan kontribusi pengaruh sebesar 61,0\%. Pengujian hipotesis diperoleh nilai $t$ hitung $>\mathrm{t}$ tabel atau $(12,370>1,984)$. Dengan demikian hipotesis yang 
diajukan bahwa terdapat berpengaruh signifikan antara kualitas produk terhadap keputusan pembelian diterima.

\section{KESIMPULAN DAN SARAN}

\section{Kesimpulan}

a. Variabel kualitas produk diperoleh ratting score sebesar 3,428 berada di rentang skala 3,40 - 4,19 dengan kriteria baik atau setuju.

b. Variabel keputusan pembelian diperoleh ratting score sebesar 3,835 berada di rentang skala 3,40 - 4,19 dengan kriteria baik atau setuju.

c. Kualitas produk berpengaruh signifikan terhadap keputusan pembelian dengan persamaan regresi $\mathrm{Y}=7,788+0,892 \mathrm{X}$, nilai korelasi sebesar 0,781 atau kuat dan kontribusi pengaruh sebesar $61,0 \%$ sedangkan sisanya sebesar 39,0\% dipengaruhi faktor lain. Uji hipotesis diperoleh nilai thitung > t tabel atau $(12,370>1,984)$.

\section{Saran}

a. Berdasarkan hasil penelitian di atas, maka penulis memberikan saran sebagai berikut:

b. Perusahaan harus selalu menjaga kualitas produk tanaman agar tetap segar dan sehat sehingga konsumen memiliki kepercayaan yang tinggi dalam memilih jenis yang akan dibelinya

c. Perusahaan juga harus mempertimbangkan faktor harga yang kompetitif dan bersaing dengan mempertimbangkan harga kompetitor.

\section{DAFTAR PUSTAKA}

Algifari. (2015). Analisis Regresi untuk Bisnis dan Ekonomi. Yogyakarta: BPFE.

Arikunto, Suharsimi (2014). Prosedur Penelitian Suatu Pendekatan Praktek. Jakarta: Rineka Cipta.

Basu Swastha Dharmmesta. (2014). Manajemen Pemasaran. BPFE: Yogyakarta. Buchari Alma. 2014. Manajemen Pemasaran dan Pemasaran Jasa. Edisi Revisi.

Bilson Simamora (2016) Panduan Riset Prilaku Konsumen, Jakarta: PT. Gramedia Pustaka.

Fandy Tjiptono (2017), Serivce Quality and Satisfiation. Jakarta: Edisi tiga. Andi.

Freddy Rangkuti (2016) Strategi Promosi Yang Kreatif, Edisi Pertama, Cetakan Pertama Jakarta: Gramedia Pustaka Utama.

Imam Ghozali (2017). Aplikasi Analisis Multivariate Dengan Program SPSS. Edisi Kelima. Semarang: Badan Penerbit Undip.

Istijanto (2014). Riset Sumber Daya Manusia. Jakarta: PT. Gramedia Pustaka

Kharis, Ismu Fadli (2011). Studi Mengenai Impulse Buying dalam Penjualan Online. Semarang : Skripsi Universitas Diponegoro

Kotler dan Amstrong (2017), Prinsip-prinsip Pemasaran. Edisi Kedua Belas". Jilid Satu. Jakarta: Erlangga.

Lupiyoadi (2016) Manajemen Pemasaran Jasa, Edisi 4, Jakarta: Salemba Empat.

Phipil Kotler dan Kevin Keller (2017) Manajemen Pemasaran, Edisi Kedua Belas, Jilid Satu, Jakarta: Erlangga.

Rao, Purba, (2012). Measuring Consumer Perceptions Through Factor Analysis. The Asian.

Santoso, Singgih (2015). Menguasai Statistik Multivariat. Jakarta: PT Elex Media Komputindo.

Sugiyono (2017). Metode Penelitian Administrasi : dilengkapi dengan Metode $R \& D$. Bandung: Alfabeta. 